\title{
NUMERICAL STUDY OF THE SMOKE PLUME OF THE JERADA THERMAL POWER PLANT MOROCCO
}

\author{
${ }^{1}$ Youssef REGAD ${ }^{*},{ }^{2}$ Bachir ELKIHEL, ${ }^{3}$ Farid BOUSHABA \\ ${ }^{4}$ Mimoun CHOURAK \\ 1,2 Team Industrial Engineering, Maintenance and Mechanical Production \\ Mohamed 1st University, National School of Applied Sciences of Oujda, BP 669, 60000 \\ Oujda, Morocco, e-mail: ${ }^{1}$ youssefregad@gmail.com, ${ }^{2}$ belkihel@yahoo.fr \\ ${ }^{3}$ Laboratory of Mechanics and Numerical Modeling, Mohamed 1st University, National \\ School of Applied Sciences of Oujda, BP 669, 60000 Oujda, Morocco \\ e-mail: f.boushaba@yahoo.fr \\ ${ }^{4}$ National School of Applied Sciences of Oujda, BP 669, 60000 Oujda, Morocco, \\ e-mail: mchourak00@gmail.com
}

Received 3 May 2018; accepted 17 October 2018

\begin{abstract}
The main goal of this study is firstly to model the phenomenon of advection and diffusion of the gaseous residues of coal combustion. On the other hand, to study the dispersion of this pollution by varying the parameters like the wind and the resources of pollution, where there are four emissions: $\mathrm{SO}_{2}, \mathrm{CO}, \mathrm{NO}_{2}$ and $\mathrm{PM}_{10}$. The present model will compare estimating concentrations with the results found by the contribution of the thermal power plant of Jerada city, where the American Environmental Regulatory Model is used. The results suggest that $\mathrm{SO}_{2}$, $\mathrm{PM}_{10}, \mathrm{NO}_{2}$ and $\mathrm{CO}$ concentration simulated by turbulent $k-\varepsilon$ model in combination with the transport model of diluted species, at the $3 \mathrm{~h}$ and $24 \mathrm{~h}$ intervals, greater than their respective observed concentrations compared with the American Environmental Regulatory Model. The concentrations of the model found are very high and exceed the limit values under the study conditions. Indeed, the simulated model was used in $2 \mathrm{D}$ with a very low wind speed $\left(10^{-4} \mathrm{~m} / \mathrm{s}\right)$ and in the absence of gravity, hence the total neglect of altitude because the two sources of pollution are at the height of $120 \mathrm{~m}$.
\end{abstract} species

Keywords: Turbulent, Diffusion, Coal, Finite-element, Combustion particle matter, Diluted

\section{Introduction}

There is a large number of scientific evidence consolidating the various health effects of air pollution, from coal-based power plants, both in terms of premature mortality and acute as well as chronic ill-health [1]. Thus, atmospheric dispersion

\footnotetext{
${ }^{*}$ Corresponding Author
} 
modeling is indeed a tool frequently used in various fields of environmental health to estimate the exposure of populations to releases from a source of pollution [2], as the present case of the city Jerada.

There has been vast experimental research in the past with increasing degrees of complexity, from Caloz's G. et al. [3], model of propagation of a smoke cloud, where he studied a simple modeling of smoke cloud propagation formulated by the $1 \mathrm{D}$ advectiondiffusion equation. An experimental study of Bhouri I. et al. [4], supported by a numerical study of a flow derived from a chimney around an obstacle where the author has studied the influence of the height of the obstacle on the plume form.

Another study done by Hao J. et al. [5], where the author studied the air quality impacts of power plant emissions in Beijing, when the control measures like fuel substitution, flue gas desulfurization, dust control improvement and flue gas denitration planned before 2008 will greatly mitigate the $\mathrm{SO}_{2}$ and $\mathrm{PM}_{10}$ pollution, especially alleviating the pressure on the urban area to reach the National Ambient Air Quality Standard (NAAQS). $\mathrm{NO}_{\mathrm{x}}$ pollution will be mitigated with $34 \%$ decrease in concentration but further controls are still needed.

In this present work, the field of study will be the Jerada thermal power plant in Morocco. An experimental study [6], was carried out in collaboration with Public Laboratory of Tests and Studies to complete the environmental impact study in order to build the $4^{\text {th }}$ group with a chimney of $120 \mathrm{~m}$ in the height and with an outside diameter of $6.40 \mathrm{~m}$, of which it will be the $3 \mathrm{rd}$ chimney in the Jerada city for 2018. Noting that for this city, the only air pollution source is this thermal power plant, which currently has three production groups, so two chimneys identical (height of $120 \mathrm{~m}$ and diameter of $6.40 \mathrm{~m}$ ) in total; the first chimney gathers the $1^{\text {st }}$ and the $2^{\text {nd }}$ group, on the other hand the $3^{\text {rd }}$ group has its own chimney. At the present time, the majorities of studies, like Cimorelli A. J. et al. (2004) [2], focus on the American Environmental Regulatory Model (AERMOD); Gaussian model, which is dedicated to the channeled and continuous releases from stationary industrial sources [2].

This study will use the data of the Jerada thermal power plant contribution to emission levels of the pollutants emitted in the current state ( 3 groups), by applying the AERMOD model [6], with the main pollutants emitted: Sulfur dioxide $\left(\mathrm{SO}_{2}\right)$; Nitrogen dioxide $\left(\mathrm{NO}_{2}\right), \mathrm{PM}_{10}$ (Particulate matter with an aerodynamic diameter of $10 \mu \mathrm{m}$ or less) and carbon monoxide (CO). Thus, the calculated parameters for each content of pollutant are: percentile $99.2^{\text {th }}$ of the $\mathrm{SO}_{2}$ daily average level, annual average concentration of $\mathrm{SO}_{2}$, percentile $98^{\text {th }}$ of the $\mathrm{NO}_{2}$ hourly average level, annual average concentration of $\mathrm{NO}_{2}$, percentile $90.4^{\text {th }}$ of the $\mathrm{PM}_{10}$ daily average level and daily maximum of the eight-hour cycles mobile average content of $\mathrm{CO}$. After, a numerical study of the thermal power plant plume will be put in place by the design of an Euler model where this modeling will discuss the reacting turbulent flow $k-\varepsilon$ with the transport of diluted species, of which it will simulate a flow in the turbulent regime coupled to species transport in air ambient. Numerical work was performed using the commercials software: Comsole Multiphysics or ANSYS Fluent Academic; engineering simulation software, for the first, it is possible to have a complete study via request a live demo, but for second one, ANSYS Student products can be downloaded by students across the globe. The experimental work using the results of the thermal power plant of 
Jerada and the measurements carried out by Public Laboratory of Tests and Studies of Oujda city [6].

The paper focuses on the analysis of the concentrations of the coal combustion residues: $\mathrm{SO}_{2}, \mathrm{CO}, \mathrm{NO}_{2}$ and $\mathrm{PM}_{10}$. The simulation results are compared with experimental work, the American Environmental Regulatory Model (Gaussian model), realized by thermal power plant and with theoretical laws in order to assess the best model that can properly diagnose the state of environmental health of Jerada city.

\section{Emissions of the Jerada thermal power plant in its current situation}

The Jerada thermal power plant was commissioned by National Office of Electricity and Water (NOEW) in 1971, this plant is equipped by three groups with a unit power of $55 \mathrm{MW}$ (total installed power $165 \mathrm{MW}$ ). It is made up of three turbo generators, with a total production capacity of $1143097000 \mathrm{kWh}$ in 2004, which constitutes $95 \%$ of the total electricity produced by the Wilaya of Oujda. At the present time, it produces only $13 \%$, due to the growth in the number of plants built, the overall production capacity of the NOEW and the increase in national consumption, specially between 2008 and $2011[6]$.

The pollutant emissions have been calculated on the basis of the actual functioning of the three groups, knowing that an hourly charge at the combustion consumption is the number of hours of each group operation.

In addition, the forecasts predict a calculation of the real-time emissions for the year (8 760 hours), according to the historical data of the three groups functioning in recent years. The situation modeled, which takes into account the simultaneous operation of the three groups throughout the year, is therefore very conservative, worst case [6].

The dust mean concentration of the ambient air measured at the reference point is equal to $21 \mathrm{mg} / \mathrm{Nm}^{3}$, which is well below the limit value $\left(50 \mathrm{mg} / \mathrm{Nm}^{3}\right)$, according to standard [7].

The characterization of the air quality in the reference situation, before the 4th group, was carried out by the Public Laboratory of Tests and Studies of Oujda city. As the measuring point is located in the Zerktouni high school precinct, its position is marked in Fig. 1. The choice of the measuring point of the air quality is based on its ideal position; proximity of the Zerktouni high school to the thermal power plant, the agglomeration of the habitats, and it is in front of the chimneys smoke of plant.

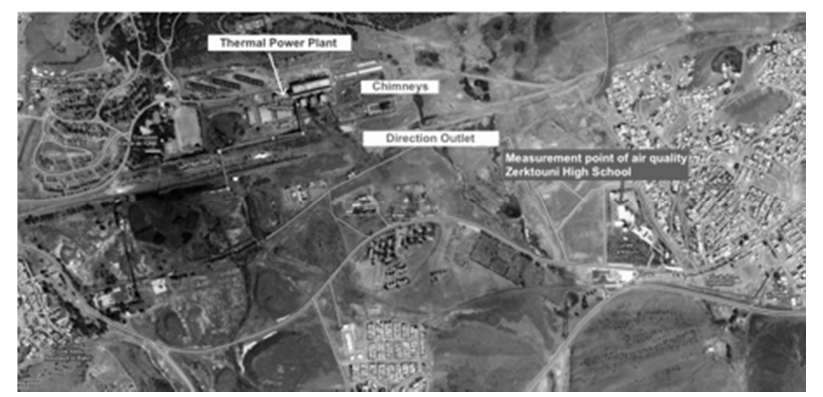

Fig. 1. The point of measurement of the air quality (Source: Google Maps (C2018) 
It is important to know the standard limits of thermal power plants according to their types and production level. In the following, this study will compare the reactions of the simulations with the normalized values, and with the values found by the plant [6].

The average emission coefficients, their standard deviation values and range for each category of plant are given by Chakraborty N. et al. [8]. The average emission coefficients for $60,67.5,210$, and $250 \mathrm{MW}$ categories of plants have been calculated, respectively [8]. The long-term goal of this work is to adapt to the changes caused by pollution, following Kovacs V. et al. [9], while trying to develop an environment conscious lifestyle in order to preserve the living-space of future generations.

\section{Computational model and governing equations}

At first, it is necessary to analyze theoretically the problem, and then a presentation of the different equations will be put in place with the parameters that manage the variability of the model. Indeed, this model combines the turbulent flow, $k-\varepsilon$ and the transport of diluted species principle. The species transport supports both a mixture, where the concentrations are of comparable order of magnitude, and low-concentration solutes in a solvent. The model can be used for stationary and time-dependent analysis in $2 \mathrm{D}$ geometries.

\subsection{The constituent physics model}

The k- $\varepsilon$ turbulence model:

The $k-\varepsilon$ model is one of the most used turbulence models for industrial applications. This module includes the standard $k-\varepsilon$ model [10]. The model introduces two additional transport equations and two dependent variables: the turbulent kinetic energy, $k$, and the turbulent dissipation rate, $\varepsilon$. The turbulent viscosity, $\mu_{T}$ is modeled as:

$$
\mu_{T}=\rho C_{\mu} \frac{k^{2}}{\varepsilon}
$$

where $C_{\mu}$ is a model constant and $\rho$ is the density, the transport equation for $k$ reads:

$$
\rho \frac{\partial k}{\partial t}+\rho(\boldsymbol{u} \cdot \nabla) k=\nabla \cdot\left(\left(\mu+\frac{\mu_{T}}{\sigma_{k}}\right) \nabla k\right)+P_{k}-\rho \varepsilon,
$$

where $\sigma_{k}$ is a model constant, $\boldsymbol{u}$ is the velocity and the production term, $P_{k}$, is:

$$
P_{k}=\mu_{T}\left(\nabla \boldsymbol{u}:\left(\nabla \boldsymbol{u}+(\nabla \boldsymbol{u})^{T}\right)-\frac{2}{3}(\nabla \cdot \boldsymbol{u})^{2}\right)-\frac{2}{3} \rho k \nabla \cdot \boldsymbol{u} .
$$

The transport equation for $\varepsilon$ reads: 


$$
\rho \frac{\partial \varepsilon}{\partial t}+\rho \boldsymbol{u} \cdot \nabla \varepsilon=\nabla \cdot\left(\left(\mu+\frac{\mu_{T}}{\sigma_{k}}\right) \nabla \varepsilon\right)+C_{\varepsilon 1} \frac{\varepsilon}{k} P_{k}-C_{\varepsilon 2} \frac{\varepsilon^{2}}{k} .
$$

The model constants in (1), (2), and (4), are determined from experimental data [11], and the values are listed in Table $I$.

Table I

Model constants

\begin{tabular}{|r|c|c|c|c|c|}
\hline Model Constant & $C_{\mu}$ & $C_{\varepsilon 1}$ & $C_{\varepsilon 2}$ & $\sigma_{k}$ & $\sigma_{\varepsilon}$ \\
\hline Value & 0.09 & 1.44 & 1.92 & 1.00 & 1.3 \\
\hline
\end{tabular}

\section{Model limitations:}

The $k-\varepsilon$ turbulence model relies on several assumptions, the most important of which is that the Reynolds number is high enough. It is also important that the turbulence is in equilibrium in boundary layers, which means that production equals dissipation. These assumptions limit the accuracy of the model because they are not always true. It does not, for example, respond correctly to flows with adverse pressure gradients and can result in under-prediction of the spatial extent of recirculation zones [10]. Furthermore, in simulations of rotating flows, the model often shows poor agreement with experimental data [11]. In most cases, the limited accuracy is a fair trade-off for the amount of computational resources saved compared to using more complicated turbulence models.

\section{Wall functions:}

The wall functions in the model are selected on the way that the computational domain is assumed to be located a distance $\delta_{W}$ from the wall. This distance is automatically computed as:

$$
\delta_{w}^{+}=\left(\rho \mu_{\tau} \delta_{w}\right) / \mu
$$

where the friction velocity is $\mu_{\tau}=C_{\mu}^{1 / 4} \sqrt{k}=10.06$, this corresponds to the distance from the wall where the logarithmic layer meets the viscous sub-layer (or to some extent would meet it if there were no buffer layer in between). The local Reynolds number $\delta_{w}^{+}$ is limited from below so that it never becomes smaller than half the height of the boundary mesh cell, to ensure that gradients of the dependent variables can be appropriately represented within the boundary layer. This means that $\delta_{w}^{+}$can become larger than 11.06 if the mesh is relatively coarse. Always investigate the solution to check that $\delta_{w}$ is small compared to the dimensions of the geometry.

Also check that $\delta_{w}^{+}$is 11.06 on most of the walls. If $\delta_{w}^{+}$is much larger than 11.06 over a significant part of the walls, the accuracy might become compromised. Both the 
wall lift-off, $\delta_{w}$ and the wall lift-off in viscous units, $\delta_{w}^{+}$are available as results and analysis variables.

The boundary conditions for the velocity are no-penetration condition $\boldsymbol{u} \cdot \boldsymbol{n}=0$, sliding stress, where $\boldsymbol{n}$ is a normal vector and the shear stress condition:

$$
\boldsymbol{\sigma} \cdot \boldsymbol{n}-(\boldsymbol{n} \cdot(\boldsymbol{\sigma} \cdot \boldsymbol{n})) \boldsymbol{n}=-\rho u_{\tau} \frac{\boldsymbol{u}}{u^{+}},
$$

where the viscous stress tensor is $\sigma=\mu\left(\nabla \boldsymbol{u}-(\nabla \boldsymbol{u})^{T}\right) ; u^{+}$is the dimensionless velocity; the velocity $\boldsymbol{u}$ parallel to the wall as a function of the distance from the wall, divided by the friction velocity $u_{\tau}=\max \left(|\boldsymbol{u}|\left(\frac{1}{\kappa_{v}} \ln \delta_{W}^{+}+\beta\right), C_{\mu}^{1 / 4} \sqrt{k}\right)$, where in turn $\kappa_{v}$ is the von Karman constant (default value 0.41), the empirical constant $\beta$ equals 5.2 for smooth walls, $\boldsymbol{u}$ is the tangential velocity, which can be used to compute the friction velocity $u_{\tau},|\boldsymbol{u}|=\sqrt{\boldsymbol{u} \cdot \boldsymbol{u}}$ is the Euclidean norm of the velocity. The turbulent kinetic energy is subject to a homogeneous Neumann condition $\boldsymbol{n} \cdot \nabla k=0$ and the boundary condition for $\varepsilon$ reads:

$$
\varepsilon=C_{\mu}^{\frac{3}{4} k \frac{3}{2}} / \kappa_{\nu} \delta_{w} .
$$

See [12] and [13], for further details.

\section{The transport of diluted species model:}

The transport of diluted species principle provides a predefined modeling environment for studying the evolution of chemical species transported by diffusion and convection. This physics assumes that all species present are dilute; that is, that their concentration is small compared to a solvent fluid (in this study: air). As a rule of thumb, a mixture containing several species can be considered dilute when the concentration of the solvent is more than $90 \mathrm{~mol} \%$. Due to the dilution, mixture properties like the density and the viscosity can be assumed to correspond to those of the solvent. Fick's law governs the diffusion of the solutes; dilute mixtures or solutions.

This physics will solve the following equations:

$$
\begin{aligned}
& \boldsymbol{N}_{i}=-D_{i} \nabla c_{i}+c_{i} \boldsymbol{u}, \\
& \frac{\partial c_{i}}{\partial t}+\nabla \cdot \boldsymbol{N}_{i}=R_{i} .
\end{aligned}
$$

It is possible to combine them together in one equation:

$$
\frac{\partial c}{\partial t}=\nabla \cdot(D \nabla c)-\nabla \cdot(\boldsymbol{u})+R,
$$


where $c$ is the variable of interest, it represents the concentration in the case of a transfer of matter, here it is the concentration of the species in $\mathrm{mol} / \mathrm{m}^{3} ; D$ denotes the diffusion coefficient in $\mathrm{m}^{2} / \mathrm{s} ; R$ is a reaction rate expression for the species, it describes 'resources' of the quantity $c$ in $\mathrm{mol} /\left(\mathrm{m}^{3} \cdot \mathrm{s}\right) ; \boldsymbol{u}$ is the velocity vector in $\mathrm{m} / \mathrm{s} ; \nabla \cdot(D \nabla c)$ describes the diffusion; and $-\nabla \cdot \boldsymbol{u}$ describes the convection (or advection).

The diffusion process can be anisotropic, in which case $\mathbf{D}$ is a tensor. This equation corresponds to a diffusion advection equation. It describes the physical phenomenon where particles are transferred to the interior of a system because of diffusion and convection.

\subsection{Geometry, boundary conditions and computational grid}

According to the location of the thermal power plant in the Jerada city, it is very clear that the dominant geometry is rectangular of dimension $x=8000 \mathrm{~m}$ and $y=6000 \mathrm{~m}$, see Fig. 2, which covers approximately the total area of the city where there are the maximum points livable by the people, because in this studied model, the priority was given to the zones of the inhabitants.

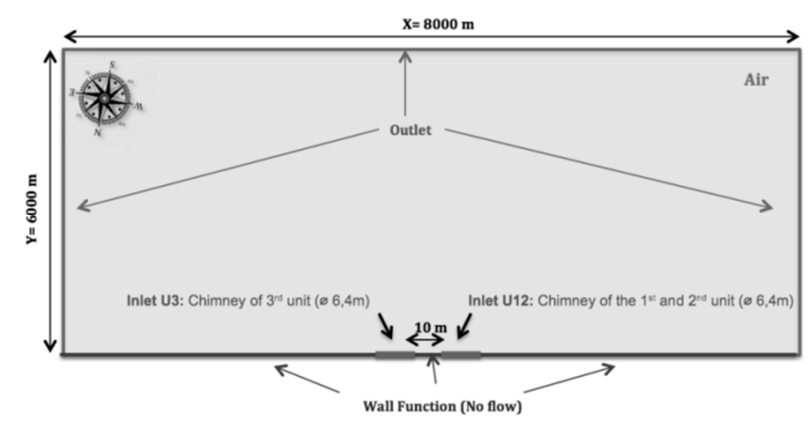

Fig. 2. Grid of the boundary conditions used for the transport of diluted species

So, by the finite element method, a mesh has been made where it is refined more in points that are very close to the sources of pollution, which is actually the only boundary conditions, as it is given in Fig. 2. The points, which are glued in the north side of the thermal power plant, have a condition of no flow, and both side walls and the top wall have flow outlet conditions.

\section{Results and discussion}

There are some parameters to define with their values, which are of crucial importance in order to use the right model of the both physical, the turbulence and the transport, and to obtain results consistent with reality. The modeling parameters are: fluid: air; particle size less than $10 \mu \mathrm{m}$; species that diffuse in the air: $\mathrm{SO}_{2}, \mathrm{PM}_{10}, \mathrm{NO}_{2}$ and $\mathrm{CO}$; coefficient of diffusion: $1.5 \cdot 10^{-2} \mathrm{~m}^{2} / \mathrm{s}$. 
For the wind speed, the model is based on very low values, at the order of some micrometers per second, $10^{-4} \mathrm{~m} / \mathrm{s}$. It is realistic as near ground speed in relatively calm conditions and calculations capabilities being limited, it is easier to stay on low speeds, to make the calculations more effective, since the atmospheric dispersion will react and propagate only by the outlet speed from the plant chimneys. The first chimney (of the $1^{\text {st }}$ and the $2^{\text {nd }}$ group) has a real flow of $303.6 \mathrm{~m}^{3} / \mathrm{s}$, with an outlet speed of the gas of $9.44 \mathrm{~m} / \mathrm{s}$, on the other hand, the second chimney (of the $3^{\text {rd }}$ group) has a real flow of $149.2 \mathrm{~m}^{3} / \mathrm{s}$, with an outlet speed of the gas of $4.64 \mathrm{~m} / \mathrm{s}$. So, the model was simulated by the finite element method [14], taking care of the creation of the geometry, the mesh, and the exploitation of result. In fact, two different times are taken to see the pollution evolution in the Jerada city: the emissions of $\mathrm{SO}_{2}, \mathrm{PM}_{10}, \mathrm{NO}_{2}$ and $\mathrm{CO}$ after 3 hours and after 24 hours from the chimneys outlet, the results are illustrated in Fig. 3 and Fig. 4.

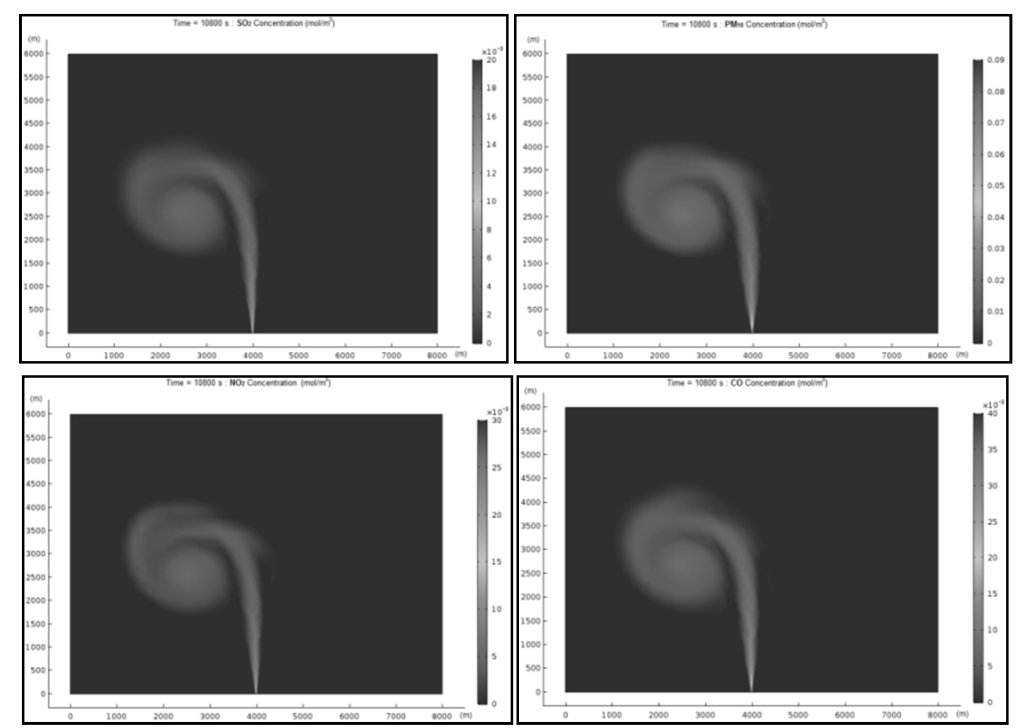

Fig. 3. Concentration $\left(\mathrm{mol} / \mathrm{m}^{3}\right)$ of the pollutants after 3 hours from the chimneys outlet

A cut line was subsequently made on the middle of the study field, the drawing of a line through the following points: 1 st point $(x=4000 \mathrm{~m}, y=0 \mathrm{~m})$ and the $2^{\text {nd }}$ point $(x=4000 \mathrm{~m}, y=6000 \mathrm{~m})$. This line will export the concentrations of the pollutant species in the direction of the propagation, respecting the same samples of the time chosen below. The figures, Fig. 5, Fig. 6, Fig. 7 and Fig. 8 represent the curves found by the same simulation.

Through the AERMOD the results of measurements of the main pollutant levels of the air are summarized in the work of the Jerada thermal power plant [6]. Measurements of the average daily concentration of $\mathrm{SO}_{2}$ from November 30 to December 2, 2012, give a value of $6.4 \mathrm{mg} / \mathrm{Nm}^{3}$. This remains well below the limit threshold $\left(99.2^{\text {th }}\right.$ percentile) set at $125 \mathrm{mg} / \mathrm{Nm}^{3}$ by the standard [7]. The average value of the $\mathrm{NO}_{2}$ concentration from 30 November to 2 December of the same year is $16.8 \mathrm{mg} / \mathrm{Nm}^{3}$, well below the limit value $\left(200 \mathrm{mg} / \mathrm{Nm}^{3}\right)$. Based on the $\mathrm{NO}_{2}$ and $\mathrm{SO}_{2}$ concentration pinks obtained, the 
dominant direction of the main pollutant emission sources from the plant is illustrated in Fig. 1 .
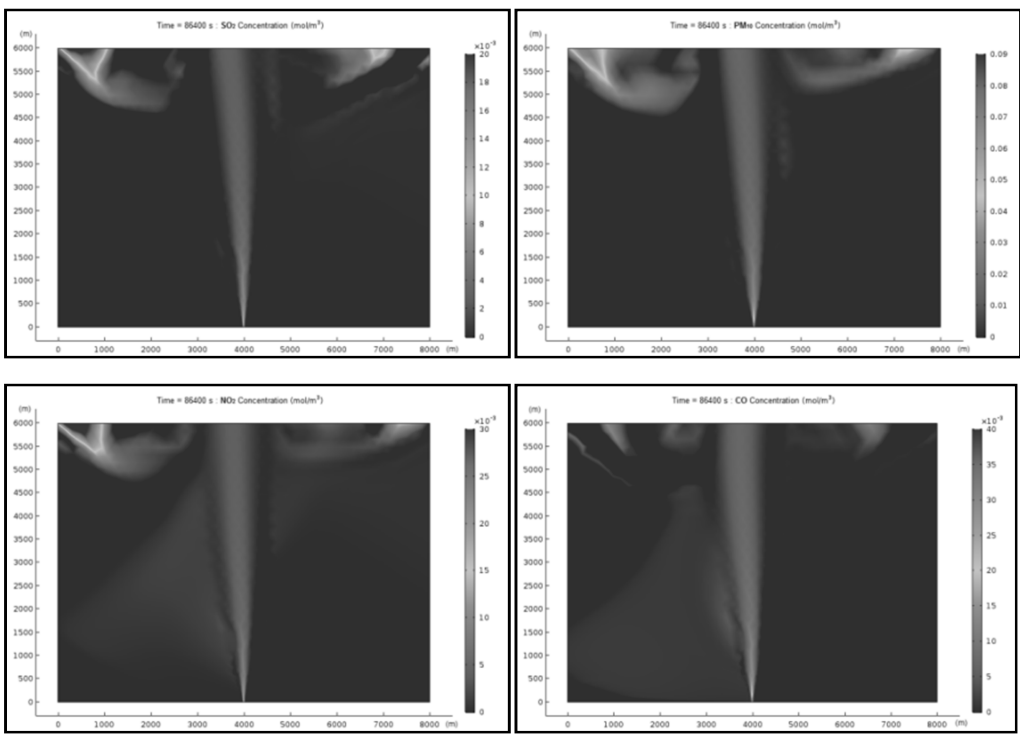

Fig. 4.Concentration $\left(\mathrm{mol} / \mathrm{m}^{3}\right)$ of the pollutants after 24 hours from the chimneys outlet

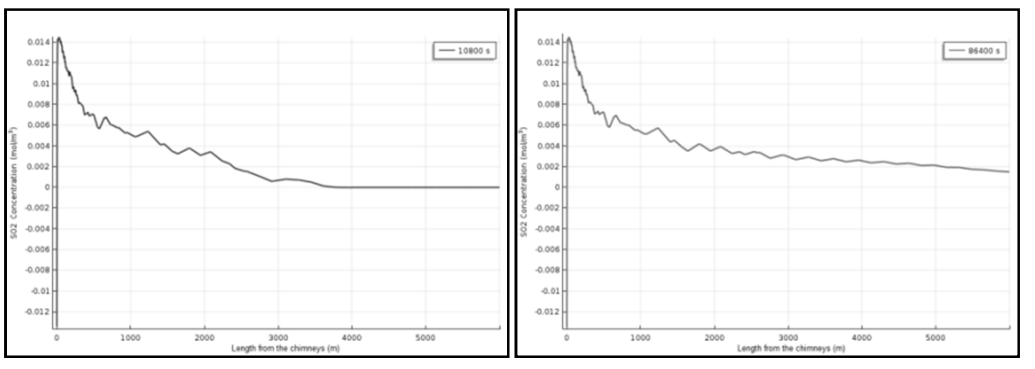

Fig. 5. The concentration evolution $\left(\mathrm{mol} / \mathrm{m}^{3}\right)$ of $\mathrm{SO}_{2}$ over time at cut line

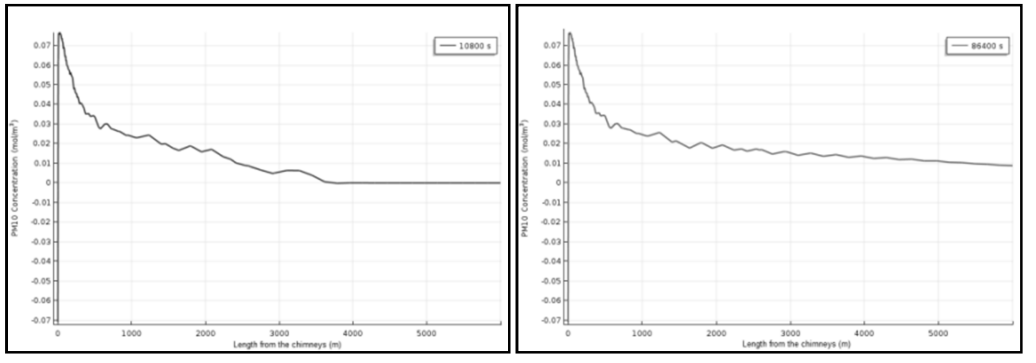

Fig. 6. The concentration evolution $\left(\mathrm{mol} / \mathrm{m}^{3}\right)$ of $\mathrm{PM}_{10}$ over time at cut line 

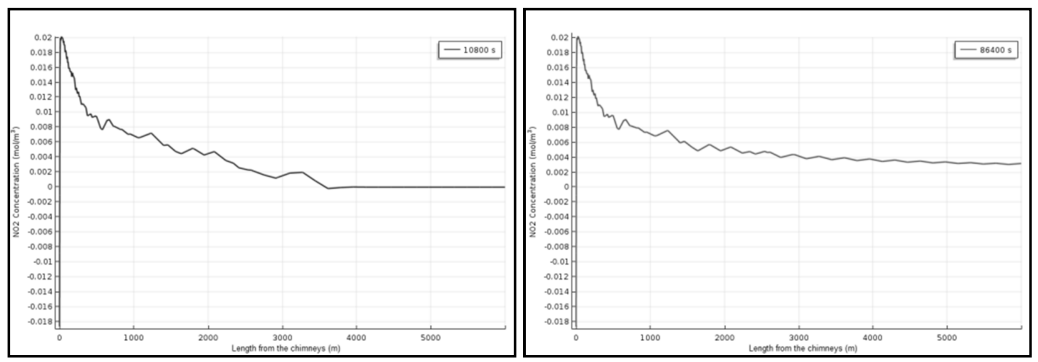

Fig. 7.The concentration evolution $\left(\mathrm{mol} / \mathrm{m}^{3}\right)$ of $\mathrm{NO}_{2}$ over time at cut line

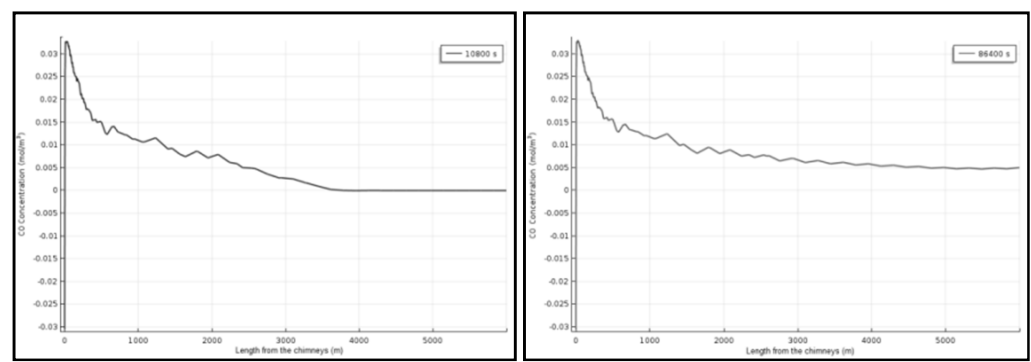

Fig. 8. The concentration evolution $\left(\mathrm{mol} /{ }^{\beta}\right)$ of $\mathrm{CO}$ over time at cut line

At the first time, the concentrations of these four species; $\mathrm{SO}_{2}, \mathrm{PM}_{10}, \mathrm{NO}_{2}$ and $\mathrm{CO}$, were simulated in $\left(\mathrm{mol} / \mathrm{m}^{3}\right)$. So, to compare the values found by the different models, the study takes, in Table II, into account the three modes: AERMOD, laboratory measurements and limit values according to the standard [7], it is necessary to convert these results into mass concentration $\left(\mathrm{g} / \mathrm{m}^{3}\right)$, knowing that the molar mass of $\mathrm{SO}_{2}, \mathrm{NO}_{2}$ and $\mathrm{CO}$ are equal,respectively, $64.066 \mathrm{~g} / \mathrm{mol}, 46.0055 \mathrm{~g} / \mathrm{mol}$ and $28.01 \mathrm{~g} / \mathrm{mol}$.

Table II

Daily results of the model to compare with those of Laboratory and AERMOD, in Zrektouni

\begin{tabular}{|l|c|c|c|c|}
\hline Concentration of: & $\mathrm{SO}_{2}$ & $\mathrm{PM}_{10}$ & $\mathrm{NO}_{2}$ & $\mathrm{CO}$ \\
\hline From $1^{\text {st }}$ Chimney at $t=0 \mathrm{~s}(\mathrm{~g} / \mathrm{s})[6]$ & 140.7 & 20.7 & 107.1 & 51.8 \\
\hline From $2^{\text {nd }}$ Chimney at $t=0 \mathrm{~s}(\mathrm{~g} / \mathrm{s})[6]$ & 72.6 & 4.5 & 55.3 & 26.7 \\
\hline AERMOD $\left(\mathrm{mg} / \mathrm{Nm}^{3}\right)$ & 14.75 & 0.900 & 24.75 & 17.83 \\
\hline $\begin{array}{l}\text { measurement of Public Laboratory of } \\
\text { Tests and Studies }\left(\mathrm{mg} / \mathrm{Nm}^{3}\right)\end{array}$ & 6.400 & 21.00 & 16.80 & $\begin{array}{c}\text { Not } \\
\text { measured }\end{array}$ \\
\hline Standard [7], $\left(\mathrm{mg} / \mathrm{Nm}^{3}\right)$ & 125.00 & 50.00 & 200.00 & 10000 \\
\hline Present model $\left(\mathrm{mol} / \mathrm{m}^{3}\right)$ & 0.0044 & 0.025 & 0.0079 & 0.0125 \\
\hline Present model $\left(\mathrm{mg} / \mathrm{Nm}^{3}\right)$ & 281.89 & 300.26 & 363.44 & 350.13 \\
\hline $\begin{array}{l}\text { Total installed power } 165 \mathrm{MW}(\mathrm{see} \text { the } \\
\text { emission per kg coal }[8])(\mathrm{g})\end{array}$ & $\begin{array}{c}12.14- \\
19.23\end{array}$ & $\begin{array}{c}\text { Not } \\
\text { measured }\end{array}$ & $\begin{array}{c}4.59- \\
3,61\end{array}$ & $\begin{array}{c}0.353- \\
1.663\end{array}$ \\
\hline
\end{tabular}

It is possible to make another comparison with the average emission coefficients [8]. Indeed, in 2011, the plant consumed 499456 tons of coal, hence the average daily 
consumption is about $1368372.60 \mathrm{~kg}$, with the density of coal is between 200 and $650 \mathrm{~kg} / \mathrm{m}^{3}$ [15], hence the justification for the calculations in the last row of Table II, with the coal density taken is the average value $425 \mathrm{~kg} / \mathrm{m}^{3}$. For $\mathrm{PM}_{10}$, the molar mass used was of carbon $\mathrm{C}\left(12.0106 \mathrm{~g} / \mathrm{m}^{3}\right)$, but in reality these particles are composed of several elements, see the chemical composition of the fly ash in the work of Regad et al. [16], since this study has already used values estimates that do not give a true reality to data and calculations; it is possible to simulate by the value of carbon C.

Therefore, on the basis of the average daily consumption of coal of $1368372.6 \mathrm{~kg}$, in 2011 [6], the present model gave a very clear idea about the air quality in the absence of the wind, worth in the calculation $10^{-4} \mathrm{~m} / \mathrm{s}$. The values found to be reasonable since the wind speed is absent in the calculation. The idea of not integrating the wind is simply to estimate the maximum values of the emissions of these four species.

So, the concentrations of the model found are very high and exceed the limit values under the study conditions.

Indeed, the simulated model was used in $2 \mathrm{D}$ with a very low wind speed $\left(10^{-4} \mathrm{~m} / \mathrm{s}\right)$ and in the absence of gravity, hence the total neglect of altitude because the two sources of pollution are at the height of $120 \mathrm{~m}$.

\section{Conclusion}

The purpose of this study was to simulate a pollution cloud in an urban environment. For this, a modeling was done in two phases; there is firstly the study of the advection and diffusion of pollutants phenomenon, and then there is the study of the dispersion of this pollution by varying the parameters like the time and the species of the pollution in Jerada city. In this paper, the study is based on the finite element method by integrating the $k-\varepsilon$ turbulence model in combination with the transport of diluted species in the city atmosphere. Thus, the comparison criterion chosen with the AERMOD model is the characterization of the air quality in the reference state, which was carried out by the Public Laboratory of Tests and Studies.

Indeed, the chosen experimental measuring point, which is the site of Zerktouni high school, is made in view of its ideal position; proximity of the plant, the agglomerations of the habitats and in front of the chimneys smoke.

The $\mathrm{SO}_{2}, \mathrm{NO}_{2}, \mathrm{PM}_{10}$ and concentrations of the model found are high and they exceed the limit values under the conditions of this simulation, sure all with the very low wind speed and in the absence of gravity.

\section{Acknowledgements}

The Authors are pleased to acknowledge the Director of Jerada thermal power plant, Morocco and the Director of the Public Laboratory of Tests and Studies of the Oujda city, Morocco for their kind permission to use their laboratories. 


\section{References}

[1] Huscher J., Holland M., Jensen G. K. The unpaid health bill, how coal power plants make us sick, Ecometrics Research and Consulting, Health and Environment Alliance, March 2013.

[2] Cimorelli A. J., Perry S. G., Venkatram A., Weil J. C., Paine R. J., Wilson R. B., Lee R. F., Peters W. D., Brode R. W., Paumier J. O. AERMOD: Description of model formulation, United States Environmental Protection Agency, 2004, No. EPA-454/R-03-004.

[3] Caloz G., Vial G. A spread model of a smoke cloud, (in French) Agrégation externe de mathématiques, Ecole Normale Supérieure, Cachan, Bretagne, 9 February 2006, pp. 1-10.

[4] Baouab I. B., Mahjoub N.S., Mhiri H., Lepalec G., Bournot P. Flow structure issued from a bent chimney around a cylindrical obstacle: Effect of the aspect ratio, Defect and Diffusion Forum, Vols. 312-315, 2011, pp. 965-970.

[5] Hao J., Wang L., Shen M, Li L., Hu J. Air quality impacts of power plant emissions in Beijing, Environmental Pollution, Vol. 147, No. 2, 2007, pp. 401-408.

[6] National Office of Electricity and Water, Electrical Branch, Environmental impact study of the Jerada thermal power plant, (in French) Clean Tech, No. SP94036P4, 2014.

[7] Minister of Energy and Minister of Health of Morocco, Order fixing the conditions and methods for calculating the air quality index, (in French) Bulletin Officiel Marocain, Vol. 6274, No. 1653-14, July 2014, pp. 3699-3701.

[8] Chakraborty N., Mukherjee I., Santra A. K., Chowdhury S., Chakraborty S., Bhattacharya S., Mitra A. P., Sharma C. Measurement of $\mathrm{CO}_{2}, \mathrm{CO}, \mathrm{SO}_{2}$, and $\mathrm{NO}$ emissions from coalbased thermal power plants in India, Atmospheric Environment, Vol. 42, No. 6, 2008, pp. 1073-1082.

[9] Kovacs V., Torok A. Environmental impact estimation of renewable gaseous fuels consumed by road vehicles, Pollack Periodica, Vol. 4, No. 3, 2009, pp. 87-97.

[10] Wilcox D. C. Turbulence modeling for CFD, Second Edition, David C. Wilcox Industries, Inc, Canada, 1998.

[11] Driver D. M., Seegmiller H. L. Features of a reattaching turbulent shear layer in diverging channel flow, American Institute of Aeronautics and Astronautics Journal, Vol. 23, No. 2 , 1985, pp. 163-171.

[12] Kuzmin D., Mierka O., Turek S. On the implementation of the k- $\varepsilon$ turbulence model in incompressible flow solvers based on a finite element discretization, Int. J. Computing Science and Mathematics, Vol. 1, No. 2, 2007, pp. 193-206.

[13] Grotjans H., Menter F. R. Wall functions for general application CFD codes, Proceedings of the Fourth European Computational Fluid Dynamics Conference, Athens, Greece, 7-11 September 1998, Vol. 1, Pts. 1-2, pp. 1112-1117.

[14] Marcsa D., Kuczmann M. Performance study of domain decomposition methods for 2D parallel finite element analysis, Pollack Periodica, Vol. 8, No. 3, 2013, pp. 47-58.

[15] The Desotec, Activated carbon density, https://www.desotec.com/en, (last visited 31 May 2018).

[16] Regad Y., Elkihel B., Delaunoid F. Valorization and characterization of CCRs of the Jerada thermal power plant in the northeast of Morocco, International Journal of Engineering and Technology, Vol. 9, No. 4, 2017, pp. 3292-3309. 